\title{
Complications in Breast Surgery
}

\author{
Angelique F. Vitug, MD, \\ Lisa A. Newman, MD, MPH, FACS* \\ University of Michigan, Breast Care Center, 1500 East Medical Center Drive, \\ 3308 CGC, Ann Arbor, MI 48167, USA
}

The breast is a relatively clean organ comprised of skin, fatty tissue, and mammary glandular elements that have no direct connection to any major body cavity or visceral structures. In the absence of concurrent major reconstruction, breast surgery generally is not accompanied by large-scale fluid shifts, infectious complications, or hemorrhage. Thus, most breast operations are categorized as low-morbidity procedures. Because the breast is the site of the most common cancer afflicting American women, however, a variety of complications can occur in association with diagnostic and multidisciplinary management procedures. Some of these complications are related to the breast itself, and others are associated with axillary staging procedures. This article first addresses some general, nonspecific complications (wound infections, seroma formation, hematoma). It then discusses complications that are specific to particular breast-related procedures: lumpectomy (including both diagnostic open biopsy and breast-conservation therapy for cancer), mastectomy; axillary lymph node dissection (ALND), lymphatic mapping/sentinel lymph node biopsy, and reconstruction. Complications related to reconstruction are discussed in a separate article in this issue.

\section{General wound complications related to breast and axillary surgery}

Because it is a peripheral soft tissue organ, many wound complications related to breast procedures are relatively minor and frequently are managed on an outpatient basis. It therefore is difficult to establish accurate incidence rates for these events. As discussed later, however, reported studies

Support for this manuscript is via an Interdisciplinary Fellowship Grant from The Susan G. Komen Breast Cancer Foundation.

* Corresponding author.

E-mail address: lanewman@umich.edu (L.A. Newman). 
document that surgical morbidity from breast and/or axillary wound infections, seromas, and hematomas occur in up to $30 \%$ of cases. Fewer than half of these cases require a prolongation of hospital stay or a readmission for inpatient care. A fourth complication, chronic incisional pain, also can occur in conjunction with various surgical breast procedures.

Rare complications that also can occur in conjunction with various breast procedures are not discussed in depth here. For example, pneumothorax can be related to either inadvertent pleural puncture during wire localization or to inadvertently deep dissection within an intercostal space. Also, patients can develop brachial plexopathy related to stretch injury caused by malpositioning in the operating room [1]. The American Society of Anesthesiology recommends upper extremity positioning such that maximal angle at the shoulder is $90^{\circ}$, with neutral forearm position, and use of padded armboards [2].

Mondor's disease, or thrombosis of the thoracoepigastric vein, can occur spontaneously, after any breast procedure such as lumpectomy, or even after percutaneous needle biopsy [3-7]. Although Mondor's disease is not an established risk factor in breast cancer, there are case reports of patients presenting with this condition at the time of the breast cancer diagnosis [4]. This condition typically presents as a palpable, sometimes tender cord running vertically from the mid-lower hemisphere of the breast toward the abdominal wall. It usually is self-limited; resolution can be expedited by soft tissue massage.

\section{Wound infections}

Rates of postoperative infections in breast and axillary incisions have ranged from less than $1 \%$ of cases to nearly $20 \%$, as shown in Table 1 [8-21]. A meta-analysis by Platt and colleagues [22] from 1993 analyzed data from 2587 surgical breast procedures and found an overall wound infection rate of $3.8 \%$ of cases. Staphylococcal organisms introduced by means of skin flora usually are implicated in these infections [8,17]. Obesity, older age, and diabetes mellitus have been some of the most consistently identified risk factors for breast wound sepsis. Several investigators have found that patients undergoing definitive surgery for cancer had a lower risk for wound infection if the diagnosis had been established by prior needle biopsy rather than by an open surgical biopsy [11,14,21], but one investigator found the opposite effect [20]. Nicotine and other components of cigarettes have well-known adverse effects on small vessels of the skin, resulting in a nearly fourfold increase in the risk of wound infection after breast surgery [19]. As demonstrated by the various studies summarized in Table 1, there is no consistent correlation between the risk of wound infection and mastectomy versus lumpectomy as definitive breast cancer surgery.

Use of preoperative antibiotic coverage to minimize infection rates has been evaluated in multiple retrospective as trials and in prospective, randomized, controlled trials. These studies have yielded disparate results; 
many have shown that a single dose of a preoperative antibiotic (usually a cephalosporin, administered approximately 30 minutes preoperatively) effectively reduces wound infection rates by $40 \%$ or more $[8,13,21,22]$, and the meta-analysis by Platt and colleagues [22] revealed that antibiotic prophylaxis reduced wound infection rates by $38 \%$, despite the selection bias of antibiotics being used predominantly in higher-risk cases. Furthermore, the lowest reported rates of breast wound infections occurred in a phase III study [16] of a long-acting versus a short-acting cephalosporin, revealing greater risk reduction with the former $(0.45 \%$ versus $0.91 \%)$. In contrast, Wagman and colleagues [10] found no effect of perioperative cephalosporin in a placebo-controlled, phase III trial involving 118 patients who had breast cancer $(5 \%$ versus $8 \%)$, however, in the antibiotic arm the infections were delayed in onset (17.7 days versus 9.6 days). Gupta and colleagues [17] reported similar rates of wound infection in a phase III study of prophylactic amoxicillin/clavulanic acid $(17.7 \%)$ versus placebo $(18.8 \%)$ and concluded that perioperative antibiotics are unnecessary in elective breast surgery. Because of these disparate results, and in an attempt to minimize cost, many clinicians limit antibiotic prophylaxis to high-risk patients and to cases involving foreign bodies, such as wire localization biopsies. Despite this common practice, it should be noted that wire localization procedures have not been identified specifically as a risk factor for wound infection [21].

Mild incisional cellulitis can be treated with oral antibiotics, but nonresponding or extensive soft tissue infection requires intravenous therapy. A minority of breast wound infections progress into a fully developed abscess. The pointing, fluctuant, and exquisitely tender mass of a breast abscess usually becomes apparent 1 to 2 weeks postoperatively and occurs at a lumpectomy, mastectomy, or axillary incision site. When there is uncertainty regarding the diagnosis (as may be the case with deep-seated abscesses after lumpectomy), ultrasound imaging is helpful occasionally, but the complex mass that is visualized can appear identical to a consolidating seroma or hematoma. Aspiration also may confirm the diagnosis, but sampling error can mislead the clinician. Definitive management of an abscess requires incision and drainage; curative aspiration of purulent material is rarely successful, and the abscess generally reaccumulates. Usually the incision and drainage can be accomplished by reopening the original surgical wound; the resulting cavity must be left open to heal by secondary intention. When recurrent cancer is a concern, biopsy of the abscess cavity wall is prudent.

Chronic recurrent periareolar abscess formation (also known as "Zuska's disease") does not necessarily develop as a consequence of primary breast surgical procedures, but this condition is notable for its high risk of complications after attempts at surgical treatment. This condition has been associated with cigarette smoking, and afflicted patients also should be checked for tuberculosis as a factor in their recurrent superficial soft tissue infections. Resection of the involved subareolar ductal system(s) frequently is offered in an attempt to break the cycle of repeated abscesses, but these procedures 
Table 1

Selected studies evaluating wound infection rates following breast surgery

\begin{tabular}{|c|c|c|c|c|c|}
\hline Study & $\begin{array}{l}\text { Number } \\
\text { of cases }\end{array}$ & $\begin{array}{l}\text { Type of procedures } \\
\text { analyzed }\end{array}$ & Type of study & $\begin{array}{l}\text { Wound infection } \\
\text { rate }(\%)\end{array}$ & $\begin{array}{l}\text { Study findings/risk factors } \\
\text { for infection }\end{array}$ \\
\hline Platt et al [8] 1990 & 606 & $\begin{array}{l}\text { Lumpectomy, } \\
\text { mastectomy, } \\
\text { ALND, reduction } \\
\text { mammoplasty }\end{array}$ & $\begin{array}{l}\text { Phase III study of } \\
\text { preoperative } \\
\text { antibiotics }\end{array}$ & 9.4 & $\begin{array}{l}\text { Preoperative antibiotic coverage reduced } \\
\text { wound infection rate ( } 6.6 \% \text { versus } \\
12.2 \%)\end{array}$ \\
\hline Hoefer et al [9] 1990 & 101 & Mastectomy & $\begin{array}{l}\text { Retrospective } \\
\text { review }\end{array}$ & 8.9 & Risk factor: cautery \\
\hline Wagman et al [10] 1990 & 118 & Mastectomy & $\begin{array}{l}\text { Phase III study of } \\
\text { preoperative } \\
\text { antibiotics }\end{array}$ & 6.8 & $\begin{array}{l}\text { Preoperative antibiotics had no effect on } \\
\text { wound infection rates }(5 \% \text { versus } 8 \%)\end{array}$ \\
\hline Chen et al [11] 1991 & - & $\begin{array}{l}\text { Mastectomy, } \\
\text { lumpectomy }\end{array}$ & $\begin{array}{l}\text { Retrospective } \\
\text { review }\end{array}$ & $2.6-11.1$ & $\begin{array}{l}\text { Risk factors: older age; surgery performed } \\
\text { in 1970s versus 1980s; prior open } \\
\text { diagnostic biopsy versus ingle-stage } \\
\text { surgery }\end{array}$ \\
\hline Vinton et al [12] 1991 & 560 & $\begin{array}{l}\text { Mastectomy, } \\
\text { lumpectomy, } \\
\text { ALND }\end{array}$ & $\begin{array}{l}\text { Retrospective } \\
\text { review }\end{array}$ & $\begin{array}{l}15 \text { (mastectomy) } \\
13 \text { (lumpectomy) }\end{array}$ & $\begin{array}{l}\text { Risk factors: older age; mastectomy } \\
\text { versus lumpectomy; tobacco smoking; } \\
\text { obesity }\end{array}$ \\
\hline Platt et al [13] 1992 & 1981 & $\begin{array}{l}\text { Mastectomy, } \\
\text { lumpectomy, } \\
\text { ALND, reduction } \\
\text { mammoplasty }\end{array}$ & $\begin{array}{l}\text { Retrospective } \\
\text { review }\end{array}$ & 3.4 & $\begin{array}{l}\text { Preoperative antibiotic coverage reduced } \\
\text { wound infection rate (odds ratio 0.59; } \\
95 \% \text { confidence interval } 0.35-0.99 \text { ) }\end{array}$ \\
\hline Lipshy et al [14] 1996 & 289 & Mastectomy & $\begin{array}{l}\text { Retrospective } \\
\text { review }\end{array}$ & 5.3 & $\begin{array}{l}\text { Risk factor: prior open diagnostic biopsy } \\
\text { versus diagnostic needle biopsy }(6.9 \% \\
\text { versus } 1.6 \%)\end{array}$ \\
\hline
\end{tabular}




\begin{tabular}{|c|c|c|c|c|c|}
\hline Bertin et al [15] 1998 & $\begin{array}{l}18 \text { cases } \\
37 \text { controls }\end{array}$ & $\begin{array}{l}\text { Mastectomy, } \\
\text { lumpectomy }\end{array}$ & Case control & NA & $\begin{array}{l}\text { Preoperative antibiotic coverage reduced } \\
\text { wound infection rate } \\
\text { Risk factors: obesity; older age }\end{array}$ \\
\hline Thomas et al [16] 1999 & 1766 & $\begin{array}{l}\text { Mastectomy, } \\
\text { lumpectomy, } \\
\text { ALND }\end{array}$ & $\begin{array}{l}\text { Phase III study of } \\
\text { preoperative } \\
\text { antibiotics }\end{array}$ & 0.6 & $\begin{array}{l}\text { Short-acting versus long-acting } \\
\text { preoperative cephalosporin }(0.91 \% \\
\text { versus } 0.45 \%)\end{array}$ \\
\hline Gupta et al [17] 2000 & 334 & $\begin{array}{l}\text { Mastectomy, } \\
\text { lumpectomy, } \\
\text { ALND }\end{array}$ & $\begin{array}{l}\text { Phase III study of } \\
\text { preoperative } \\
\text { antibiotics }\end{array}$ & 18.3 & $\begin{array}{l}\text { Preoperative antibiotics had no effect on } \\
\text { wound infection rates }(17.7 \% \text { versus } \\
18.8 \%)\end{array}$ \\
\hline Nieto et al [18] 2002 & 107 & $\begin{array}{l}\text { Mastectomy, } \\
\text { lumpectomy, } \\
\text { ALND }\end{array}$ & $\begin{array}{l}\text { Prospective } \\
\text { observational } \\
\text { study }\end{array}$ & $\begin{array}{l}7 \text { (mastectomy) } \\
17 \text { (lumpectomy) }\end{array}$ & $\begin{array}{l}\text { Risk factors: lumpectomy versus } \\
\text { mastectomy; older age; obesity }\end{array}$ \\
\hline Sorensen et al [19] 2002 & 425 & $\begin{array}{l}\text { Mastectomy, } \\
\text { lumpectomy, } \\
\text { ALND }\end{array}$ & $\begin{array}{l}\text { Retrospective } \\
\text { review }\end{array}$ & 10.5 & $\begin{array}{l}\text { Risk factors: tobacco smoking; diabetes } \\
\text { mellitus; obesity; heavy ethanol } \\
\text { consumption }\end{array}$ \\
\hline Witt et al [20] 2003 & 326 & $\begin{array}{l}\text { Mastectomy, } \\
\text { lumpectomy, } \\
\text { ALND }\end{array}$ & $\begin{array}{l}\text { Prospective } \\
\text { observational } \\
\text { study }\end{array}$ & 15.3 & $\begin{array}{l}\text { Risk factors: older age; obesity; diabetes } \\
\text { mellitus; prior diagnostic core needle } \\
\text { biopsy versus open diagnostic biopsy }\end{array}$ \\
\hline Tran et al [21] 2003 & 320 & $\begin{array}{l}\text { Mastectomy, } \\
\text { lumpectomy }\end{array}$ & $\begin{array}{l}\text { Retrospective } \\
\text { review }\end{array}$ & 6.1 & $\begin{array}{l}\text { Preoperative antibiotic coverage reduced } \\
\text { wound infection rate } \\
\text { Risk factors: prior open diagnostic biopsy } \\
\text { versus diagnostic needle biopsy ( } 11.1 \% \\
\text { versus } 9.7 \% \text { ) }\end{array}$ \\
\hline
\end{tabular}

Abbreviations: ALND, axillary lymph node dissection; NA, not applicable. 
often are themselves complicated by wound infections and by chronically draining sinus tracts. Some patients suffering from the most refractory cases have resorted to complete resection of the entire nipple-areolar complex, but this strategy certainly should be reserved as a last-ditch effort.

\section{Seroma}

The rich lymphatic drainage of the breast from intramammary lymphatics to the axillary, supraclavicular, and internal mammary nodal basins establishes the tendency for seroma formation within any closed space that results from breast surgery. It has been proposed that the low fibrinogen levels and net fibrinolytic activity within lymphatic fluid collections account for seroma formation $[23,24]$. The closed spaces of lumpectomy cavities, axillary wounds, and the anterior chest wall cavity left under mastectomy skin flaps can all harbor seroma. After a lumpectomy, this seroma is advantageous to the patient, because it usually preserves the normal breast contour even after a large-volume resection, eventually being replaced by scar formation as the cavity consolidates. Occasionally the lumpectomy seroma is overly exuberant. If the patient experiences discomfort from a bulging fluid collection, simple aspiration of the excess is adequate management.

Seroma formation under the skin flaps of axillary or mastectomy wounds impairs the healing process; therefore drains are usually left in place to evacuate postoperative fluid collections. Most breast cancer surgery is performed in the outpatient setting, and patients must be instructed about proper drainage catheter care. After 1 to 3 weeks, the skin flaps heal and adhere to the chest wall, as evidenced by diminished drain output. Seroma collections that develop after drain removal can be managed by percutaneous aspiration. Aspiration usually is well tolerated because the mastectomy and axillary incisions tend to be insensate; these procedures can be repeated as frequently as necessary to ensure that the skin flaps are densely adherent to the chest wall. Seroma aspiration is necessary in $10 \%$ to $80 \%$ of ALND and mastectomy cases, according to reported series and as reviewed in detail by Pogson and colleagues [23]. Axillary surgery limited to the sentinel lymph node biopsy seems to confer a lower risk of seroma formation, but this procedure usually is performed without drain insertion; therefore occasional patients require subsequent seroma aspiration [25].

Several investigators have studied strategies that might minimize seroma formation to decrease the time that drainage catheters are needed or to obviate their need altogether. Talbot and Magarey [26] subjected 90 consecutive patients who had breast cancer undergoing ALND to (1) conventional, prolonged closed-suction drainage; (2) 2-day short-term drainage; or (3) no drainage. There were no differences in the rates of infectious wound complications in the three groups, and at a minimum follow-up of 1 year there were no differences in lymphedema risk. In group 1, the drain was removed at a median of nearly 10 days, with $73 \%$ of cases requiring subsequent seroma 
aspiration. As expected, the short-term and no-drain groups required more frequent seroma aspirations ( $86 \%$ and $97 \%$, respectively). The mean duration of suction drainage and/or aspiration drainages was similar for all three groups (25-27 days). In all groups fluid accumulation had mostly resolved by 4 weeks, but in each group there were a few patients (approximately $16 \%$ ) who had prolonged drainage lasting an additional 2 to 3 weeks. Similar findings have been reported in older studies $[27,28]$. The number of drains used and the use of low- versus high-vacuum suction do not seem to affect the results achieved with drainage catheters.

Shoulder immobilization with slings or special wraps to decrease seroma formation also has been proposed, but this approach carries the risk of possible long-term range-of-motion limitations and even may increase the risk of lymphedema [29]. A reasonable alternative approach endorsed by most breast surgeons is to recommend that patients simply limit motion at the shoulder to abduction no greater than $90^{\circ}$ and that active upper extremity physiotherapy be delayed until drainage catheters have been removed. This strategy seems to decrease seroma formation more effectively than early physiotherapy programs and does not adversely affect long-term range-of-motion results [30,31].

The tissue effects of electrocautery are a well-recognized risk factor for increased seroma formation [23]. Two prospective clinical trials have randomly assigned patients who have breast cancer to undergo surgery with electrocautery or with scalpel only and have confirmed the lower incidence of seroma formation with the latter technique $[32,33]$. Few surgeons, however, are willing to relinquish the convenience and improved hemostasis associated with electrocautery dissection.

In a study from France, Classe and colleagues [34] reported successful use of axillary padding in lieu of catheter drains in 207 patients who had breast cancer undergoing ALND and found seroma formation in $22.2 \%$. In contrast, the Memorial Sloan Kettering Cancer Center conducted a clinical trial that randomly assigned 135 patients undergoing ALND to receive a compression dressing for 4 days or standard wound coverage (all patients had conventional catheter drainage as well). This study found no benefit from compression dressings [35]. Both arms of this study had similar total drainage volumes and drainage catheter durations, and the compression arm furthermore had increased need for seroma aspiration (mean number of aspirations, 2.9 in the compression arm compared with 1.8 in the standard dressing arm; $P<.01)$.

Chemical maneuvers to decrease seroma formation also have been investigated. Application of tetracycline as a sclerosing agent has been ineffective [36]. Bovine thrombin similarly has been unsuccessful in this regard [37]. Use of fibrin glues, patches, and/or sealants has seemed promising, but clinical studies in humans have yielded inconsistent results, and it therefore is unclear whether the added expense of these agents is justified $[23,38-40]$. 


\section{Hematoma}

Widespread use of electrocautery has reduced the incidence of hematoma formation in breast surgery dramatically, but this complication continues to occur in $2 \%$ to $10 \%$ of cases. Some cases of low-volume hematoma carry low morbidity, leaving the patient with a more extensive ecchymosis as the adjacent soft tissues absorb the hematoma. At the other end of the spectrum, large hematomas can be quite painful because of rapid expansion through the closed wound space and should be evacuated surgically, with aggressive wound irrigation and reclosure to optimize cosmesis.

An ongoing debate in breast surgery has revolved around defining the optimal technique for closure of a lumpectomy cavity. Leaving the cavity open to fill with seroma and closing the overlying skin with deep dermal sutures and a final subcuticular layer has become a conventional wound-closure strategy. This method allows prompt restoration of the breast contour through rapid filling of the lumpectomy cavity by seroma, but it requires meticulous attention to ensuring hemostasis along the lumpectomy cavity walls before skin closure. Many others therefore advocate the use of absorbable sutures to reapproximate the deeper lumpectomy tissues, and this maneuver has been reported to decrease the risk of hematoma complications [41]. The disadvantage of using the deep cavity sutures is the potential for compromising the final cosmetic result by altering the underlying breast architecture and causing focal areas of retraction.

The use of a support brassiere in the postoperative period will bolster efforts to sustain hemostasis and relieves tension on the skin closure imposed by the weight of the breast. This precaution can be especially important with large, pendulous breasts, in which blood vessels running alongside the cavity can be avulsed mechanically if the heavy breast is allowed to suspend unsupported. The patient should be encouraged to wear the support brassiere day and night for several days.

The use of particular medications in the perioperative period also has been implicated in the risk for bleeding complications. Aspirin-containing products and nonsteroidal anti-inflammatory drugs such as ibuprofen have well-known antiplatelet activity, and these medications should be avoided for 1 to 2 weeks before surgery (the lifespan of the affected platelets). Ketorolac has become a popular intravenous substitute for opiate analgesics during the postoperative period, but this agent also is characterized as a nonsteroidal anti-inflammatory drug and should be used cautiously to minimize risk of hematoma [42]. In addition, several widely used over-the-counter medications and herbal supplements have become recognized recently for contributing to a bleeding diathesis; these include ginseng, ginkgo biloba, and garlic [43,44].

\section{Chronic pain}

A minority of breast cancer patients experience chronic incisional pain that can be quite debilitating and refractory to standard analgesics, lasting 
for several months to years postoperatively. The exact etiology of this syndrome remains obscure, although it commonly is assumed to be neuropathic in nature. Frequently described as a "burning," "constricting," or "lancingtype" ache, it is reported among mastectomy as well as lumpectomy patients and often is accompanied by ipsilateral upper extremity symptoms. The incidence of this chronic pain syndrome is uncertain, but it has been reported to afflict $20 \%$ to $30 \%$ of patients who are specifically queried [45-49]. Surprisingly, it has been reported to occur more commonly after lumpectomy than after mastectomy $[45,49]$. Risk factors identified with this syndrome include younger age, larger tumors, radiation therapy, chemotherapy, depression, and poor coping mechanisms $[46,49,50]$. The occasionally intractable quality of this syndrome causes substantial frustration for both patients and surgeons. Fortunately, recent successful management has been reported with use of serotonin uptake inhibitors, such as the antidepressants amitriptyline and venlafaxine [51].

\section{Venous thromboembolism}

Cancer is an established risk factor for hypercoagulable states [52,53] and therefore is a risk factor for postoperative venous thromboembolic (VTE) complications. Breast surgical procedures (in the absence of immediate reconstruction) tend not to be prolonged cases, however, and many are performed on an ambulatory, outpatient basis. Therefore the usefulness of routinely prescribing systemic VTE prophylaxis for patients who have breast cancer (as has been advocated for patients undergoing surgery for other types of cancer) and who lack some other predisposition for VTE has been questioned. Furthermore, the risk of wound hematoma after breast and/or axillary surgery can be tripled by the practice of systemic anti-VTE prophylaxis [54]. Andtbacka and colleagues [55] studied this issue in 3898 patients undergoing surgery for breast cancer at the University of Texas M.D. Anderson Cancer Center (with anti-VTE management consisting of early ambulation and compression stockings only) and reported a VTE rate of $0.16 \%$, detected at a median time of 2 weeks after surgery. The authors concluded that the risk of VTE after breast surgery is sufficiently low that systemic VTE prophylaxis is not indicated.

\section{Complications specific to mastectomy procedures}

\section{Incisional dog-ears}

Heavyset patients who have thick axillary fat pads are especially prone to being left with triangular or cone-shaped flaps of redundant skin and fatty tissue along the lateral aspect of the mastectomy incision, commonly known as "dog-ears." Frequently the incisional dog-ear is not readily apparent while the patient is lying supine on the operating room table, but when 
she sits or stands upright postoperatively, these unsightly protrusions of axillary fat become obvious. Because they are irritating to the ipsilateral upper extremity, these flaps create significant discomfort for the patient. Similar to the inframammary fold before mastectomy, these dog-ears sometimes can be sites for recurrent candidal/yeast infections.

Numerous surgical approaches have been recommended to prevent or eliminate the dog-ear problem. One option is to bring the redundant axillary tissue forward and create a " $\mathrm{T}$ " or " $\mathrm{Y}$ " configuration at the lateral aspect of the transverse mastectomy incision [56]. Alternatively, the redundant axillary skin and fatty tissue can be resected either by elongating the standard elliptical mastectomy wound or by using a broad tear-drop incision, with the point of the tear-drop oriented medially $[57,58]$.

\section{Complications specific to lumpectomy procedures}

\section{Breast fibrosis, breast lymphedema, and chronic/recurrent breast cellulitis}

The presence of long-term adverse sequelae related to breast-conservation therapy for cancer is being acknowledged and reported increasingly $[59,60]$. These complications are secondary to the combined tissue effects of surgery and radiation therapy. The European Organization for Research and Treatment and the Radiation Therapy Oncology Group have proposed that late effects of breast-conservation therapy (including breast edema, fibrosis, and atrophy/retraction) be graded according to the Late Effects of Normal Tissue-Subjective, Objective, Management, and Analytic (LENTSOMA) scales [61]. The LENT-SOMA system stratifies breast symptoms on the basis of pain magnitude as reported by the patient, measurable differences in breast appearance, need for intervention to control pain and/or lymphedema, and presence of image-documented breast sequelae (eg, photographs, mammography, CT/MRI, and other studies).

Using the LENT-SOMA four-point grading system, Fehlauer and colleagues [60] reported grade 3 to grade 4 toxicity in $4 \%$ to $18 \%$ of patients who had breast cancer treated between 1983 and 1984 (radiation therapy fractionation schedule, $2.5 \mathrm{~Gy}$ four times per week to $60 \mathrm{~Gy}$; median follow-up duration, 171 months), and these rates declined to $2 \%$ or less for patients treated in 1994 and 1995 (radiation therapy fractionation schedule, 2.0 Gy five times per week to $55 \mathrm{~Gy}$; median follow-up duration, 75 months). These findings suggest that extent of side effects is a function of both followup duration and radiation delivery technique. Similarly, Meric and colleagues [59] reported chronic breast symptoms in $9.9 \%$ of patients who had breast cancer treated by lumpectomy and radiation from 1990 to 1992 and followed for at least 1 year after treatment.

Recurrent episodes of breast cellulitis occurring several months to years after lumpectomy and/or breast radiation therapy is reported to afflict fewer 
than $5 \%$ of patients, but this unusual and delayed complication causes significant concern because of the need to rule out an inflammatory breast cancer recurrence [62-66]. This condition can present as a myriad of scenarios: acutely inflamed seroma formation, localized mastitis, or diffuse breast pain and swelling. Repeat breast imaging is indicated to look for parenchymal features suggesting recurrence, such as an underlying spiculated mass or calcifications; if such features are present, an image-guided biopsy should be pursued. Otherwise benign-appearing cases that are refractory to a standard course of antibiotics should undergo punch biopsy for further evaluation. Occasionally patients ultimately request mastectomy because of intractable pain and inflammation.

The cause of delayed breast edema and cellulitis is incompletely understood but is assumed to be related to lymphatic obstruction affecting intramammary drainage. Risk factors for this condition include a history of early postoperative complications such as hematoma and seroma; upper extremity lymphedema; and large-volume lumpectomies [63]. Most cases have followed resection of upper outer quadrant tumors. Rarely is a causative bacterial pathogen identified in these cases, but the conventional management nonetheless includes antibiotic coverage for skin flora. The development of this complication does not seem to carry any cancer-related prognostic significance.

\section{Complications related to lumpectomy and brachytherapy}

Several breast cancer programs are currently exploring strategies of partial breast irradiation that allow shortening of the conventional 5- to 6-week external beam program. One such strategy involves insertion of a balloontype catheter (the MammoSite applicator; MammoSite Radiation Therapy System, MammoSite RTS, CYTYC, Palo Alto, California) into the lumpectomy cavity for delivery of brachytherapy. This device typically is inserted in the operating room at the time of lumpectomy, with the expectation that margin control will be achieved; if this is not the case, additional surgery and a second implantation is required. While investigations of the longterm efficacy of these accelerated breast-irradiation programs are being conducted, experience with catheter-related risks is accumulating. CT imaging is performed subsequently to ensure adequate balloon placement, as defined by a minimum applicator-skin distance of $5 \mathrm{~mm}$, and appropriate conformance, with uniform contact between the balloon and lumpectomy walls. Optimal positioning can be challenging but is essential for delivery of therapy with minimal risk of local complications.

Results from a prospective, multicenter study of the MammoSite device revealed that of 70 patients enrolled, $21(30 \%)$ could not complete the study because of lumpectomy-related issues (cavity size, skin spacing, or conformance) [67]. Of the 54 patients who had a balloon inserted, $57 \%$ experienced overlying skin erythema, and 2 patients developed wound infections, including one abscess. 


\section{Angiosarcoma related to breast-conservation therapy}

Reviewed in detail by Monroe and colleagues [68], angiosarcomas of the breast following lumpectomy and radiation therapy for breast cancer are rare but are being reported with increasing infrequency. These secondary angiosarcomas are to be distinguished from primary breast angiosarcomas, which occur in relatively younger women and which have no well-defined risk factors. Secondary angiosarcomas occur 4 to 10 years after primary breast cancer treatment [68-70]. Lymphedema-related extremity angiosarcoma (Stewart-Treves syndrome, discussed later) has a longer latency period from time of breast cancer treatment. Furthermore, the occurrence of breast angiosarcomas in the irradiated field coupled with the implications for genetic predisposition to radiation-induced tumorigenesis (eg, ataxia-telangiectasia) has prompted speculation that these lesions have an etiology different from that of Stewart-Treves syndrome. Median survival, however, is similarly poor, at 1 to 3 years [68].

\section{Complications specific to diagnostic open biopsy procedures}

\section{Sampling error}

The primary potential risk specifically associated with a diagnostic open biopsy is related to missing a cancerous lesion and resecting adjacent fibrocystic tissue, thereby misdiagnosing the patient. This complication exists with palpable masses as well as with screen-detected nonpalpable lesions.

The risk of misdiagnosis with palpable breast masses can be minimized by complete preoperative breast imaging, including mammography and ultrasonography. Palpable lesions that have a suspicious-appearing imaging correlate should have an initial attempt at percutaneous core needle biopsy to establish a diagnosis. If malignancy is confirmed, cancer-directed management options can be addressed promptly. In eligible patients who have measurable disease, neoadjuvant chemotherapy is one option that offers the potential benefits of tumor downstaging to improve the success of breastconservation therapy and of monitoring chemosensitivity [71]. If the percutaneous biopsy was performed freehand, and results are nondiagnostic, an image-guided needle biopsy (by either ultrasound or stereotactic/mammographic) can be attempted. Alternatively, if resources are available, the percutaneous biopsy may be performed with image guidance as the initial maneuver to improve the diagnostic accuracy.

If the palpable lesion does not have an imaging correlate, or if needle biopsy strategies are unavailable, a diagnostic open biopsy must be performed. Sampling errors with these procedures are uncommon, but sampling in patients who have extensive fibrocystic changes can be challenging, especially when the lesion is a self-detected mass that is less apparent on clinical examination. In these cases the breast should be assessed and marked just before surgery by the surgeon and patient together, but 
intraoperative surgical judgment remains critical, and any suspicious masses identified within the open breast wound should be biopsied and oriented appropriately.

The risk of sampling error with nonpalpable breast lesions is greater. Establishing a diagnosis for clinically occult lesions that are identified by mammogram or ultrasound necessarily depends on image guidance. As noted previously, there are advantages to proceeding with an image-guided percutaneous needle biopsy as the initial diagnostic strategy. Patients whose diagnosis pf cancer has been made by needle biopsy are more likely to have successful breast-conservation therapy and to require fewer re-excisions for margin control than patients who undergo an initial open biopsy for diagnostic purposes [72]. A core-needle biopsy is preferable to a fine-needle aspiration biopsy because he larger tissue yield can distinguish in situ from invasive architecture and also because the sampling error with a fine-needle aspiration biopsy can be as high as $30 \%$, compared with only $5 \%$ to $10 \%$ with a core needle. If the targeted lesion is small and can be resected completely within the core specimens, a radiopaque clip should be left in place to facilitate subsequent localization in case surgery is required.

When high-risk lesions such as atypical hyperplasia, radial scar, or lobular carcinoma in situ are identified on core-needle biopsy, a follow-up open surgical biopsy should be performed. The sampling error rates associated with these findings are substantial, and $10 \%$ to $40 \%$ will be upstaged to cancer on subsequent open biopsy [73].

Open surgical biopsies of nonpalpable, image-detected breast lesions require image-guided wire localization. The localizing wire can be inserted under either ultrasound or mammographic guidance, depending on which modality best images the abnormal lesion. MRI-guided wire localization technology is available in some centers as well. Past strategies for localization have included external skin markings and preoperative injection of dye into the vicinity of the lesion, but these techniques have been largely abandoned because of higher sampling error rates. Insertion of a hooked wire, with two-view confirmatory mammography of the wire position in relation to the abnormal lesion, followed by mammographic (and/or ultrasonographic) imaging of the biopsy specimen to document inclusion of the suspicious target, is the most widely used technique in contemporary breast programs. With this algorithm, the target is likely to be missed in fewer than $5 \%$ of cases. Risk factors for a sampling error complication despite these precautions include suboptimal wire localization, migration of the localizing wire between the time of insertion and the time of surgical resection, and migration of a previously inserted clip that was intended to mark the site of a prior core-needle biopsy. When a sampling error is recognized intraoperatively, based on specimen imaging, it is quite difficult to reorient the breast anatomy intraoperatively without the localizing wire. In this circumstance it is prudent to resist multiple attempts at blind biopsies, because the likelihood of success is low, and the additional tissue resections will compromise 
cosmesis. The patient should be informed of the failed procedure, and repeat imaging should be repeated 2 to 4 weeks postoperatively, with plans for another wire localization made accordingly.

\section{Complications related to axillary staging procedures}

The axillary nodal status remains the most powerful prognostic feature in staging patients who have invasive breast cancer. Surgical staging of the axilla is necessary for most newly diagnosed patients, because currently available imaging modalities can easily miss small nodal metastases. The conventional level I/II ALND is the standard means of evaluating the axilla, but lymphatic mapping and sentinel lymph node biopsy has emerged recently as a viable alternative strategy for accurately determining the nodal status. Each of these staging procedures is associated with risks for various complications and is discussed separately.

\section{Complications associated with auxiliary lymph node dissection}

The level I/II ALND is the conventionally accepted staging procedure. Random axillary sampling procedures and ALND limited to level I can miss metastases in $20 \%$ to $25 \%$ of cases. On the other hand, a level III dissection generally is considered unnecessary (unless grossly apparent disease is present in the axillary apex), because skip metastases to level III only occur in $2 \%$ to $3 \%$ of cases. The presence of an axillary arch has been proposed as an anatomic variant that can increase the risk of sampling error when a standard level I and II ALND is performed [74]. The axillary arch is formed by an aberrant segment of latissimus dorsi muscle that extends toward the pectoralis. If the axillary dissection does not encompass the lymphatic tissue lateral to these fibers, significant nodal tissue can be missed. Failure to appreciate this anatomic variant has been implicated as a cause for subsequent axillary recurrence [75].

Upper extremity lymphedema is the complication that has generated the most concern after ALND, because it is a lifelong risk following the procedure and, when it occurs, is quite refractory to treatment. Lymphedema has been reported to develop in $13 \%$ to $27 \%$ of patients who have breast cancer [25,76-79], but detection rates vary based on how closely patients are followed and duration of follow-up. The risk of lymphedema is greater after a higher-level axillary dissection than after less extensive surgery but has been reported to occur even after axillary surgery limited to the sentinel lymph nodes [25]. Other risk factors include obesity and regional radiation therapy. Patients can minimize the risk of lymphedema by participating in an aggressive and regulated physical therapy program, and onset of this problem is aggravated by upper extremity trauma or infection.

One of the most feared long-term sequelae of chronic lymphedema is the development of upper extremity angiosarcoma [80,81]. This condition is also 
known as "Stewart-Treves syndrome" [82], named for the investigators who first reported a series of cases demonstrating the association between postmastectomy lymphedema and the onset of this malignancy. Stewart-Treves syndrome typically appears as bluish-reddish macular lesions or nodules on the skin of the ipsilateral upper extremity. This disease generally develops approximately 10 years after treatment for breast cancer, and it is usually (but not always) seen in patients whose risk of lymphedema has been amplified by regional irradiation in addition to ALND. Treatment strategies have included wide local excision, amputation, chemotherapy, and/or radiation, with disappointing results. Most patients succumb to hematogenously disseminated metastases to lung and visceral organs, with a median survival of approximately 2 years.

The axillary dissection surgical bed exposes the axillary vein, thoracodorsal, long thoracic ("nerve of Bell"), and intercostobrachial nerves, as well as the neurovascular bundle to the pectoralis musculature. The intercostobrachial nerves are sacrificed routinely during a conventional ALND because they course directly through the nodal tissue en route to the skin of the axilla and upper inner arm, leaving patients with sensory deficits in this distribution. Attempts to preserve these nerves can result in damage that leaves the patient with chronic neuropathic pain of the involved skin. The axillary vein is at risk for hemorrhagic complications as a consequence of direct injury or thrombosis secondary to traction and/or compression. The axillary artery and brachial plexus are relatively protected from intraoperative damage because of their deeper and more superior location. The thoracodorsal neurovascular bundle, which courses along the inner aspect of the latissimus dorsi muscle, should be exposed completely and preserved intact, unless there is gross encasement by nodal metastases. Sacrifice of these structures denervates the latissimus (leaving the patient with weakness of internal rotation and shoulder abduction) and renders the thoracodorsal vessels unavailable for possible future use in conjunction with microvascular anastomoses for free flap reconstructions. Disruption of the long thoracic nerve results in loss of serratus anterior function and a winged scapula deformity with an unsightly posterior shoulder bony protrusion. When the medial and lateral pectoral nerves are transected, denervation atrophy of the pectoral muscles eventually becomes apparent and can compromise the cosmetic result substantially.

Axillary webs are bands of scar tissue that develop after ALND in fewer than $10 \%$ of cases. They are readily apparent as cordlike structures coursing from the surgical bed toward the forearm and occasionally reaching the thumb [83]. They cause significant tightness and limitation of motion but in most cases resolve within a few months. Physical therapy and massage are frequently helpful in alleviating symptoms.

One final rare complication of the ALND is chyle leak, sometimes reputed to be secondary to thoracic duct injury [84]. Recently, octreotide has been recommended to control extensive lymphorrhea [85]. 


\section{Complications associated with lymphatic mapping and sentinel lymph node biopsy}

In 1993 and 1994 the initial reports of lymphatic mapping and sentinel lymph node biopsy for patients who had breast cancer appeared in the literature, by Krag and colleagues [86] using radiolabeled isotope, and by Giuliano and colleagues [87] using blue dye. The accuracy of the sentinel lymph node biopsy procedure is discussed elsewhere in this issue, but the procedure now is widely accepted for axillary staging in breast cancer.

Complications that have been reported after a sentinel lymph node biopsy are the same as those associated with ALND, including seroma, lymphedema, axillary web formation, and neurosensory disturbances, but the magnitude of risk is lower. Data on long-term follow-up of patients who have undergone sentinel lymph node biopsy alone are revealing adverse sequelae in fewer than $10 \%$ of cases $[25,78,88,89]$. Wilke and colleagues [89] reported on the outcomes of 5327 patients who had early-stage breast cancer participating in the American College of Surgeons Oncology Group prospective lymphatic mapping protocol and found axillary wound infections in $1 \%$, axillary seroma in $7.1 \%$, and axillary hematoma in $1.4 \%$. Lymphedema was reported in $6.9 \%$ of cases.

Allergic reactions to the blue dye used for mapping procedures can occur with the use of isosulfan blue as well as patent blue dye. Within a few minutes to an hour after blue dye injection, up to $2 \%$ of patients may experience sudden hemodynamic instability and other sequelae of intraoperative anaphylaxis. Despite the dramatic presentation, these episodes usually respond readily to supportive care, which includes discontinuation of the gaseous anesthetics, $100 \%$ oxygen, aggressive fluid resuscitation, and pressor support. In most cases the anesthesia and surgical procedure have been resumed and completed uneventfully after the patient has been stabilized. Some surgeons, however, have elected to abort the surgical procedure and to reschedule the mapping without blue dye [90]. In one reported case, a planned lumpectomy was converted to a mastectomy so that the allergen focus would be resected completely [91]. Many other patients have proceeded to undergo successful lumpectomies, but they should be monitored closely for 24 hours because continued uptake of the blue dye from skin and soft tissue can result in protracted or delayed secondary (biphasic) reactions.

Blue urticaria, a less severe form of blue dye allergy characterized by bluetinged hives, is another pattern that has been reported [92,93]. There is no correlation with past allergy history, and preoperative skin testing is unreliable in identifying highest-risk patients. One hypothesis is that many individuals have prior sensitization from exposure to industrial dyes in cosmetics, textiles, detergents, and other products. Routine premedication of all patients undergoing mapping with steroids, antihistamines, and/or histamine receptor blockade has been proposed, but the added expense and risks of this approach for a low-incidence allergic reaction have not been documented. Known 
allergy to triphenylmethane is a contraindication to blue dye use. Thus far, methylene blue seems to be less allergenic [94], but caution must be exercised to avoid skin necrosis from dermal injections of this agent.

Blue dyes also can cause a spurious decline in pulse oximetry measurements, related to intravascular uptake and interference with spectroscopy; in these circumstances arterial blood gases reveal normal oxygenation. Blue dyes are contraindicated during pregnancy, because the risk of teratogenicity is unknown.

\section{References}

[1] Grunwald Z, Moore JH, Schwartz GF. Bilateral brachial plexus palsy after a right-side modified radical mastectomy with immediate TRAM flap reconstruction. Breast J 2003;9(1):41-3.

[2] Warner M, Blitt C, Butterworth J, et al. Practice advisory for the prevention of perioperative peripheral neuropathies. A report by the American Society of Anesthesiologists' Task Force on the prevention of perioperative peripheral neuropathies. Anesthesiology 2000;92: $1168-82$.

[3] Bejanga BI. Mondor's disease: analysis of 30 cases. J R Coll Surg Edinb 1992;37(5):322-4.

[4] Catania S, Zurrida S, Veronesi P, et al. Mondor's disease and breast cancer. Cancer 1992; 69(9):2267-70.

[5] Harris AT. Mondor's disease of the breast can also occur after a sonography-guided core biopsy. AJR Am J Roentgenol 2003;180(1):284-5.

[6] Hou MF, Huang CJ, Huang YS, et al. Mondor's disease in the breast. Kaohsiung J Med Sci 1999;15(11):632-9.

[7] Jaberi M, Willey SC, Brem RF. Stereotactic vacuum-assisted breast biopsy: an unusual cause of Mondor's disease. AJR Am J Roentgenol 2002;179(1):185-6.

[8] Platt R, Zaleznik DF, Hopkins CC, et al. Perioperative antibiotic prophylaxis for herniorrhaphy and breast surgery. N Engl J Med 1990;322(3):153-60.

[9] Hoefer R, DuBois J, Ostrow L, et al. Wound complications following modified radical mastectomy: an analysis of perioperative factors. J Am Osteopath Assoc 1990;90:47-53.

[10] Wagman LD, Tegtmeier B, Beatty JD, et al. A prospective, randomized double-blind study of the use of antibiotics at the time of mastectomy. Surg Gynecol Obstet 1990; 170(1):12-6.

[11] Chen J, Gutkin Z, Bawnik J. Postoperative infections in breast surgery. J Hosp Infect 1991; 17:61-5.

[12] Vinton AL, Traverso LW, Jolly PC. Wound complications after modified radical mastectomy compared with tylectomy with axillary lymph node dissection. Am J Surg 1991; 161(5):584-8.

[13] Platt R, Zucker JR, Zaleznik DF, et al. Prophylaxis against wound infection following herniorrhaphy or breast surgery. J Infect Dis 1992;166(3):556-60.

[14] Lipshy KA, Neifeld JP, Boyle RM, et al. Complications of mastectomy and their relationship to biopsy technique. Ann Surg Oncol 1996;3(3):290-4.

[15] Bertin M, Crowe J, Gordon S. Determinants of surgical site infection after breast surgery. Am J Infect Control 1998;26:61-5.

[16] Thomas R, Alvino P, Cortino GR, et al. Long-acting versus short-acting cephalosporins for preoperative prophylaxis in breast surgery: a randomized double-blind trial involving 1,766 patients. Chemotherapy 1999;45(3):217-23.

[17] Gupta R, Sinnett D, Carpenter R, et al. Antibiotic prophylaxis for post-operative wound infection in clean elective breast surgery. Eur J Surg Oncol 2000;26(4):363-6.

[18] Nieto A, Lozano M, Moro MT, et al. Determinants of wound infections after surgery for breast cancer. Zentralbl Gynakol 2002;124(8-9):429-33. 
[19] Sorensen LT, Horby J, Friis E, et al. Smoking as a risk factor for wound healing and infection in breast cancer surgery. Eur J Surg Oncol 2002;28(8):815-20.

[20] Witt A, Yavuz D, Walchetseder C, et al. Preoperative core needle biopsy as an independent risk factor for wound infection after breast surgery. Obstet Gynecol 2003;101(4):745-50.

[21] Tran CL, Langer S, Broderick-Villa G, et al. Does reoperation predispose to postoperative wound infection in women undergoing operation for breast cancer? Am Surg 2003;69(10): $852-6$.

[22] Platt R, Zucker JR, Zaleznik DF, et al. Perioperative antibiotic prophylaxis and wound infection following breast surgery. J Antimicrob Chemother 1993;31(Suppl B):43-8.

[23] Pogson CJ, Adwani A, Ebbs SR. Seroma following breast cancer surgery. Eur J Surg Oncol 2003;29(9):711-7.

[24] Bonnema J, Ligtensetein D, Wiggers T, et al. The composition of serous fluid after axillary dissection. Eur J Surg 1999;165:9-13.

[25] Giuliano AE, Haigh PI, Brennan MB, et al. Prospective observational study of sentinel lymphadenectomy without further axillary dissection in patients with sentinel node-negative breast cancer. J Clin Oncol 2000;18(13):2553-9.

[26] Talbot ML, Magarey CJ. Reduced use of drains following axillary lymphadenectomy for breast cancer. ANZ J Surg 2002;72(7):488-90.

[27] Cameron AE, Ebbs SR, Wylie F, et al. Suction drainage of the axilla: a prospective randomized trial. Br J Surg 1988;75(12):1211.

[28] Somers R, Jablon L, Kaplan M. The use of closed suction drainage after lumpectomy and axillary dissection for breast cancer: a prospective randomized trial. Ann Surg 1992;215: $146-9$.

[29] Flew J. The effect of restriction of shoulder movement. Br J Surg 1979;66:302-5.

[30] Lotz M, Duncan M, Gerber L, et al. Early versus delayed shoulder motion following axillary dissection. Ann Surg 1981;193:288-95.

[31] Schultz I, Barrholm M, Grondal S. Delayed shoulder exercises in reducing seroma frequency after modified radical mastectomy: a prospective randomized study. Ann Surg Oncol 1997;4: 293-7.

[32] Porter KA, O'Connor S, Rimm E, et al. Electrocautery as a factor in seroma formation following mastectomy. Am J Surg 1998;176(1):8-11.

[33] Keogh G, Doughty J, McArdle C, et al. Seroma formation related to electrocautery in breast surgery-a prospective, randomized trial. Breast 1998;7:39-41.

[34] Classe J, Dupre P, Francois T, et al. Axillary padding as an alternative to closed suction drain for ambulatory axillary lymphadenectomy. Arch Surg 2002;137:169-73.

[35] O'Hea BJ, Ho MN, Petrek JA. External compression dressing versus standard dressing after axillary lymphadenectomy. Am J Surg 1999;177(6):450-3.

[36] Rice DC, Morris SM, Sarr MG, et al. Intraoperative topical tetracycline sclerotherapy following mastectomy: a prospective, randomized trial. J Surg Oncol 2000;73(4):224-7.

[37] Burak WE Jr, Goodman P, Young D. Seroma formation following axillary dissection for breast cancer: risk factors and lack of influence of bovine thrombin. J Surg Oncol 1997;64:27-31.

[38] Langer S, Guenther JM, DiFronzo LA. Does fibrin sealant reduce drain output and allow earlier removal of drainage catheters in women undergoing operation for breast cancer? Am Surg 2003;69(1):77-81.

[39] Berger A, Tempfer C, Hartmann B, et al. Sealing of postoperative axillary leakage after axillary lymphadenectomy using a fibrin glue coated collagen patch: a prospective randomised study. Breast Cancer Res Treat 2001;67(1):9-14.

[40] Moore M, Burak WE Jr, Nelson E, et al. Fibrin sealant reduces the duration and amount of fluid drainage after axillary dissection: a randomized prospective clinical trial. J Am Coll Surg 2001;192(5):591-9.

[41] Paterson ML, Nathanson SD, Havstad S. Hematomas following excisional breast biopsies for invasive breast carcinoma: the influence of deep suture approximation of breast parenchyma. Am Surg 1994;60(11):845-8. 
[42] Sharma S, Chang DW, Koutz C, et al. Incidence of hematoma associated with ketorolac after TRAM flap breast reconstruction. Plast Reconstr Surg 2001;107(2):352-5.

[43] Hodges P, Kam P. The perioperative implications of herbal medicines. Anaesthesia 2002; 57(9):889-99.

[44] Ang-Lee M, Moss J, Yuan C. Herbal medicines and perioperative care. JAMA 2001;286(2): $208-16$.

[45] Tasmuth T, von Smitten K, Kalso E. Pain and other symptoms during the first year after radical and conservative surgery for breast cancer. Br J Cancer 1996;74(12): 2024-31.

[46] Tasmuth T, Blomqvist C, Kalso E. Chronic post-treatment symptoms in patients with breast cancer operated in different surgical units. Eur J Surg Oncol 1999;25:38-43.

[47] Stevens P, Dibble S, Miastowski C. Prevalence, characteristics, and impact of postmastectomy pain syndrome: an investigation of women's experiences. Pain 1995;61:61-8.

[48] Carpenter J, Andrylkowski M, Sloan P, et al. Postmastectomy/postlumpectomy pain in breast cancer survivors. J Clin Epidemiol 1998;51:1285-92.

[49] Tasmuth T, von Smitten K, Hietanen P, et al. Pain and other symptoms after different treatment modalities of breast cancer. Ann Oncol 1995;6:453-9.

[50] Bishop SR, Warr D. Coping, catastrophizing and chronic pain in breast cancer. J Behav Med 2003;26(3):265-81.

[51] Tasmuth T, Hartel B, Kalso E. Venlafaxine in neuropathic pain following treatment of breast cancer. Eur J Pain 2002;6(1):17-24.

[52] Rickles FR, Edwards RL. Activation of blood coagulation in cancer: Trousseau's syndrome revisited. Blood 1983;62(1):14-31.

[53] Duggan C, Marriott K, Edwards R, et al. Inherited and acquired risk factors for venous thromboembolic disease among women taking tamoxifen to prevent breast cancer. J Clin Oncol 2003;21(19):3588-93.

[54] Friis E, Horby J, Sorensen LT, et al. Thromboembolic prophylaxis as a risk factor for postoperative complications after breast cancer surgery. World J Surg 2004;28(6): $540-3$.

[55] Andtbacka RH, Babiera G, Singletary SE, et al. Incidence and prevention of venous thromboembolism in patients undergoing breast cancer surgery and treated according to clinical pathways. Ann Surg 2006;243(1):96-101.

[56] Farrar WB, Fanning WJ. Eliminating the dog-ear in modified radical mastectomy. Am J Surg 1988;156(5):401-2.

[57] Chretien-Marquet B, Bennaceur S. Dog ear: true and false. A simple surgical management. Dermatol Surg 1997;23(7):547-50 [discussion: 551].

[58] Mirza M, Sinha KS, Fortes-Mayer K. Tear-drop incision for mastectomy to avoid dog-ear deformity. Ann R Coll Surg Engl 2003;85(2):131.

[59] Meric F, Buchholz TA, Mirza NQ, et al. Long-term complications associated with breastconservation surgery and radiotherapy. Ann Surg Oncol 2002;9(6):543-9.

[60] Fehlauer F, Tribius S, Holler U, et al. Long-term radiation sequelae after breast-conserving therapy in women with early-stage breast cancer: an observational study using the LENTSOMA scoring system. Int J Radiat Oncol Biol Phys 2003;55(3):651-8.

[61] LENT-SOMA scales for all anatomic sites. Int J Radiat Oncol Biol Phys 1995;31: 1049-91.

[62] Zippel D, Siegelmann-Danieli N, Ayalon S, et al. Delayed breast cellulitis following breast conserving operation. Eur J Surg Oncol 2003;29(4):327-30.

[63] Brewer VH, Hahn KA, Rohrbach BW, et al. Risk factor analysis for breast cellulitis complicating breast conservation therapy. Clin Infect Dis 2000;31(3):654-9.

[64] Staren ED, Klepac S, Smith AP, et al. The dilemma of delayed cellulitis after breast conservation therapy. Arch Surg 1996;131(6):651-4.

[65] Rescigno J, McCormick B, Brown AE, et al. Breast cellulitis after conservative surgery and radiotherapy. Int J Radiat Oncol Biol Phys 1994;29(1):163-8. 
[66] Miller SR, Mondry T, Reed JS, et al. Delayed cellulitis associated with conservative therapy for breast cancer. J Surg Oncol 1998;67(4):242-5.

[67] Keisch M, Vicini F, Kuske RR, et al. Initial clinical experience with the MammoSite breast brachytherapy applicator in women with early-stage breast cancer treated with breast-conserving therapy. Int J Radiat Oncol Biol Phys 2003;55(2):289-93.

[68] Monroe AT, Feigenberg SJ, Mendenhall NP. Angiosarcoma after breast-conserving therapy. Cancer 2003;97(8):1832-40.

[69] Edeiken S, Russo DP, Knecht J, et al. Angiosarcoma after tylectomy and radiation therapy for carcinoma of the breast. Cancer 1992;70(3):644-7.

[70] Feigenberg SJ, Mendenhall NP, Reith JD, et al. Angiosarcoma after breast-conserving therapy: experience with hyperfractionated radiotherapy. Int J Radiat Oncol Biol Phys 2002; 52(3):620-6.

[71] Fisher B, Brown A, Mamounas E, et al. Effect of preoperative chemotherapy on localregional disease in women with operable breast cancer: findings from National Surgical Adjuvant Breast and Bowel Project B-18. J Clin Oncol 1997;15(7):2483-93.

[72] Liberman L, Goodstone S, Dershaw D. One operation after percutaneous diagnosis of nonpalpable breast cancer: frequency and associated factors. AJR Am J Roentgenol 2002;178: 673-9.

[73] Newman L. Surgical management of high-risk breast lesions. Curr Probl Surg 2004.

[74] Petrasek AJ, Semple JL, McCready DR. The surgical and oncologic significance of the axillary arch during axillary lymphadenectomy. Can J Surg 1997;40(1):44-7.

[75] Wright FC, Walker J, Law CH, et al. Outcomes after localized axillary node recurrence in breast cancer. Ann Surg Oncol 2003;10(9):1054-8.

[76] Erickson VS, Pearson ML, Ganz PA, et al. Arm edema in breast cancer patients. J Natl Cancer Inst 2001;93(2):96-111.

[77] Beaulac SM, McNair LA, Scott TE, et al. Lymphedema and quality of life in survivors of early-stage breast cancer. Arch Surg 2002;137(11):1253-7.

[78] Sener SF, Winchester DJ, Martz CH, et al. Lymphedema after sentinel lymphadenectomy for breast carcinoma. Cancer 2001;92(4):748-52.

[79] Roses DF, Brooks AD, Harris MN, et al. Complications of level I and II axillary dissection in the treatment of carcinoma of the breast. Ann Surg 1999;230(2):194-201.

[80] Grobmyer SR, Daly JM, Glotzbach RE, et al. Role of surgery in the management of postmastectomy extremity angiosarcoma (Stewart-Treves syndrome). J Surg Oncol 2000;73(3): $182-8$.

[81] Janse AJ, van Coevorden F, Peterse H, et al. Lymphedema-induced lymphangiosarcoma. Eur J Surg Oncol 1995;21(2):155-8.

[82] Stewart FW, Treves N. Classics in oncology: lymphangiosarcoma in postmastectomy lymphedema: a report of six cases in elephantiasis chirurgica. CA Cancer J Clin 1981;31(5):284-99.

[83] Moskovitz AH, Anderson BO, Yeung RS, et al. Axillary web syndrome after axillary dissection. Am J Surg 2001;181(5):434-9.

[84] Caluwe GL, Christiaens MR. Chylous leak: a rare complication after axillary lymph node dissection. Acta Chir Belg 2003;103(2):217-8.

[85] Carcoforo P, Soliani G, Maestroni U, et al. Octreotide in the treatment of lymphorrhea after axillary node dissection: a prospective randomized controlled trial. J Am Coll Surg 2003; 196(3):365-9.

[86] Krag DN, Weaver DL, Alex JC, et al. Surgical resection and radiolocalization of the sentinel lymph node in breast cancer using a gamma probe. Surg Oncol 1993;2(6):335-9 [discussion: 340].

[87] Giuliano AE, Kirgan DM, Guenther JM, et al. Lymphatic mapping and sentinel lymphadenectomy for breast cancer. Ann Surg 1994;220(3):391-8 [discussion: 398-401].

[88] Leidenius M, Leppanen E, Krogerus L, et al. Motion restriction and axillary web syndrome after sentinel node biopsy and axillary clearance in breast cancer. Am J Surg 2003;185(2): $127-30$. 
[89] Wilke LG, McCall LM, Posther KE, et al. Surgical complications associated with sentinel lymph node biopsy: results from a prospective international cooperative group trial. Ann Surg Oncol 2006;13(4):491-500.

[90] Laurie SA, Khan DA, Gruchalla RS, et al. Anaphylaxis to isosulfan blue. Ann Allergy Asthma Immunol 2002;88(1):64-6.

[91] Efron P, Knudsen E, Hirshorn S, et al. Anaphylactic reaction to isosulfan blue used for sentinel node biopsy: case report and literature review. Breast J 2002;8(6):396-9.

[92] Sadiq TS, Burns WW 3rd, Taber DJ, et al. Blue urticaria: a previously unreported adverse event associated with isosulfan blue. Arch Surg 2001;136(12):1433-5.

[93] Cimmino VM, Brown AC, Szocik JF, et al. Allergic reactions to isosulfan blue during sentinel node biopsy—a common event. Surgery 2001;130(3):439-42.

[94] Mostafa A, Carpenter R. Anaphylaxis to patent blue dye during sentinel lymph node biopsy for breast cancer. Eur J Surg Oncol 2001;27:610. 